UDC 536:636

LBC 40.77

\title{
INFRARED HEATING SYSTEMS OF POULTRY HOUSES MICROCLIMATE
}

\author{
Aleksey V. Sklyar \\ OOO "Big Dutchman", Moscow, Russian Federation; \\ Big Dutchman AG (holding) Auf der Lage, Vechta, Germany \\ Margarita V. Postnova \\ Volgograd State University, Volgograd, Russian Federation
}

\begin{abstract}
The urgency of solving the problem of heat losses on heating mains and central boiler houses in poultry houses is important, since the efforts of poultry farms are focused on improving the devices and heating systems in the poultry houses themselves. One of the directions of the solution of this problem is the use of exclusive qualities of infrared heating in the variant where its specific advantages of selective heating of a given object are revealed as much as possible, excluding intermediate heat carriers. Thus, the calculation of the relationship of dark infryared heating systems in addition to traditional microclimatic systems in poultry farms from different regions of the Russian Federation has shown high efficiency in the operation of this design.
\end{abstract}

Key words: poultry farms, heating, infrared heating, air, broiler.

УДК 536:636

ББК 40.77

\section{ИНФРАКРАСНЫЙ ОБОГРЕВ В СИСТЕМАХ МИКРОКЛИМАТА ПТИЧНИКОВ}

\section{Алексей Владимирович Скляр}

ООО «Биг Дачмен», г. Москва, Российская Федерация;

Big Dutchman AG (холдинг), Vechta, Германия

\section{Маргарита Викторовна Постнова}

Волгоградский государственный университет, г. Волгоград, Российская Федерация

\begin{abstract}
Аннотация. Актуальность решения проблемы тепловых потерь на теплотрассах и центральных котельных в птичниках важно, так как усилия птицеводческих хозяйств сосредоточены на совершенствовании приборов и систем обогрева в самих птичниках. Одним из направлений решения данной задачи является использование эксклюзивных качеств инфракрасного обогрева именно в том варианте, где максимально раскрываются его специфические достоинства избирательного нагрева заданного объекта, исключая промежуточные теплоносители. Таким образом, расчет взаимосвязи темновых систем инфракрасного обогрева в дополнение к традиционным микроклиматическим системам в птицеводческих хозяйствах из разных регионов РФ показал высокую эффективность в эксплуатации данной конструкции.
\end{abstract}

Ключевые слова: птицеводческие хозяйства, отопление, инфракрасный обогрев, воздух, бройлер.

В птицеводстве РФ особо актуальным остается вопрос отопления птицеводческих

залов - в зависимости от региона птичник приходится оснащать $250 \ldots 650$ киловаттной сис(2) темой обогрева для обеспечения норматив- ного продуцирования поголовья $[1 ; 3 ; 4 ; 7]$. Проблема тепловых потерь на теплотрассах и в центральных котельных была решена с переводом птичников на локальный обогрев и сейчас усилия птицеводческих хозяйств со- 
средоточены на совершенствовании приборов и систем обогрева в самих птичниках [6]. Одно из направлений - использование эксклюзивных качеств инфракрасного (ИК) обогрева именно в том варианте, где максимально раскрываются его специфические достоинства избирательного нагрева заданного объекта, исключая промежуточные теплоносители (воздух, воду и т. п.).

При этом в первую очередь должна анализироваться возможность применения неэлектрических ИК-обогревателей, а устройств работающих, например, на газовом топливе. Это, естественно, из-за эффективности - 1 м $^{3}$ газа по ГОСТ 5542-87 [2] с теплосодержанием 8000 ккал эквивалентен 8000/860 = 9,3 кВт/ч, а с учетом коэффициента полезного действия (КПД) всех устройств, преобразующих его в электричество, эффект снижается до 2,73 кВТ/ч, то есть практически трехкратная экономическая выгода прямого использования газа на обогрев очевидна. Реальные цены $1 \mathrm{~m}^{3}$ газа и 1 кВТ/ч электроэнергии на практике близки и варьируют в пределах 4,9...5,6 рублей и потому в стоимостном выражении результат внедрения газового ИК-обогрева будет столь же эффективным. На сегодня по факту электрический обогрев - самый дорогой вид отопления и применение его допустимо лишь в ситуациях, когда нет альтернативных вариантов.

Анализ особенностей ИК-обогрева (физики процесса), тех требований к конструкции таких обогревателей и условий их эффективного функционирования позволяет отделить ряд технологий промышленного птицеводства, где применение газовых ИК-обогревателей в настоящее время вряд ли возможно [5]. Это клеточные технологии выращивания и содержания всех видов и стад птицы: яичные куры промышленные стада несушек, родительского стада и ремонтного молодняка, бройлеры, утята, индюшата легких кроссов и перепела.

По напольным технологиям, где объективно нет очевидных препятствий для внедрения энергоэкономичного ИК-отопления в первую очередь должна быть решена задача нормативного нагрева в холодный и переходные периоды года больших объемов приточного воздуха, составляющего по уравнению теплового баланса основные затраты на отопление птичников в 5,5-6 раз превышающие, например, тепловые потери через ограждения. Наиболее продуктивным представляется совмещение этих систем с созданием гибридных схем, включающих традиционные отопительно-вентиляционные и ИК-блоки.

ИК-отопителями эффективно снижать затраты тепла на обогрев птицы уже сегодня можно путем замены энергоемких морально устаревших электробрудеров, широко используемых во всех напольных технологиях в стартовый период откорма бройлеров. На стадии выращивания нормативная аэрация минимальна (воздух в птицеводческом зале по $\mathrm{CO}_{2}$ заменяется 4-6 раз в час), а нагрев притока предельный - до $30 \ldots 33{ }^{\circ} \mathrm{C}$. Держать такую температуру на весь объем птицеводческого зала нерационально из-за увеличения тепловых потерь (с вытяжным воздухом и через ограждения) и практически невозможности обеспечить нормальные условия для работы персонала. Сейчас этот вопрос решается локальным обогревом зоны размещения птицы (под брудерами до $33{ }^{\circ} \mathrm{C}$ ) при фоновой температуре зала $23 . .28^{\circ} \mathrm{C}$. Это громоздкое переносное оборудование и трудовых затратная технология. Подвеска брудеров и установка ограждений, выделяющих зоны обогрева, с последующим их демонтажом, затрудняется тем, что брудера и ограду надо ставить среди линий кормления и поения. Нормативная потребность на типовой бройлерник $96 \times 18 \times 3$ м - 60 брудеров БП-1А с установленной мощностью 66 кВт. Их замена системой из 3-х длинноволновых газовых ИК-обогревателей той же суммарной мощности $(L=15 \mathrm{M})$ позволяет разместить все суточное поголовье птицеводческого зала более комфортно (71 против $40 \mathrm{~cm}^{2} /$ гол. в брудеpe, то есть в 1,77 раза) и при этом снизить затраты по оплате обогрева из-за перехода на газ в 2,8-3,4 раза. Капитальные затраты на ИКобогрев (3 установки по 102 тыс. руб.) также не превышают цены 60 брудеров (по 12-18 тыс. руб./шт.) даже с учетом стоимости подводки газа и установки ИК-обогревателей в птичнике. Темновые системы ИК-обогрева хорошо дополняют традиционные микроклиматические системы птичников по пиковому обогреву молодняка на старте. Нами были выполнены расчеты по взаимоувязке этих систем и ряду птицехозяйств в разных регионах РФ постав- 
лен значительной объем комплексных систем, где они показали высокую эффективность в эксплуатации («ПензаМолИнвест», Пензенская обл., ЗАО Краснобор, Тульская обл. и др.).

Особо надо отметить ряд дополнительных достоинств темновых ИК-обогревателей:

1) помимо дополнительного тепла на старте они позволяют микроклиматической системе птичника преодолевать все холодовые пики зимы по всему диапазону наружных температур от уровня наиболее холодной 5-дневки до абсолютного минимума без снижения воздухообеспечения поголовья ниже $0,7 \mathrm{~m}^{3} /$ кг живой массы птицы в час;

2) не сушат воздух при высоком КПД обогрева птицы, т.к. их излучение не нагревает воздушную массу птицеводческого зала, поскольку тепло выделяется только на поверхностях, куда падают эти лучи (птица, подстилка, люди и т. п.), Эта особенность позволяет снизить фоновую температуру птицеводческого зала и обеспечивает основную экономию тепла (при брудерах нельзя охлаждать фон-простудятся цыплята при выходе из под нагревателя);

3) работа на минимальных температуpax ИК-излучения $\left(200 \ldots 350{ }^{\circ} \mathrm{C}\right)$ длинноволнового диапазона (5,6-100 мкм), обеспечивает не только безвредное не ограниченное по времени пребывание птицы и человека в зоне их действия, но и создает птице комфортные условия содержания (эти ИК-лучи в медицине используется для лечения);

4) размещение темновых ИК-обогревателей в птичниках не мешает типовой расстановке технологического оборудования в целом по объему здания, у них имеют безопасное закрытое пламя с выходом продуктов сжигания газа наружу;

5) время прогрева птичника в зимний период года, перед посадкой птицы, снижается в 3-4 раза.

\section{СПИСОК ЛИТЕРАТУРЫ}

1. Аглиуллина, Э. Р. Особенности инфракрасного обогрева помещений / Э. Р. Аглиуллина // Материалы XI Международной учебно-научнопрактической конференции «Трубопроводный транспорт-2016».-2016. -C. 333-334.
2. ГОСТ 5542-87. - Электрон. текстовые дн. Режим доступа: http://docs.cntd.ru/document/ 1200001400 (дата обращения: 01.11. 2018).

3. Дубровин, А. В. Управление тепловым комфортом, обогревом и микроклиматом птичника по экономическому критерию / А. В. Дубровин // Материалы международной научно-технической конференции «Научно-технический прогресс в сельскохозяйственном производстве. Аграрная наука - сельскохозяйственному производству Сибири, Казахстана, Монголии, Беларуси и Болгарии». 2016. -C. 18-22.

4. Куриленко, Н. И. Особенности регулирования систем газового инфракрасного обогрева / Н. И. Куриленко, Р. Р. Давлятчин, А. Н. Ермолаев // Инженерный вестник Дона. - 2015. № 2-2 (36). - С. 126.

5. Санжаровская, М. И. Энергосбережение при применении инфракрасного излучения для отопления животноводческих и других помещений / М. И. Санжаровская // Инженерно-техническое обеспечение АПК. Реферативный журнал. - 2008. № 2. - C. 592.

6. Хайруллин, Д. А. Принцип инфракрасного обогрева // Д. А. Хайруллин, Т. Р. Терегулов // European Science . - 2016. - № 12 (22). C. $13-14$.

7. Чулин, В. Р. Инфракрасные системы обогрева / В. Р. Чулин, И. Ю. Шелехова, В. В. Пожидаев // Материалы международной научно-практической конференции «Роль науки в развитии современного государства». -2018 . - С. 133-139.

\section{REFERENCES}

1. Agliullina Je.R. Osobennosti infrakrasnogo obogreva pomeshhenij [Features of infrared heating]. Mat.XI Mezhdunarodnoj uchebno-nauchnoprakticheskoj konferencii "Truboprovodnyj transport - 2016», 2016, pp.333-334.

2. GOST 5542-87. URL: http://docs.cntd.ru/ document/1200001400 (accessed 01 November 2018).

3. Dubrovin A.V. Upravlenie teplovym komfortom, obogrevom i mikroklimatom ptichnika po jekonomicheskomu kriteriju [Management of thermal comfort, heating and microclimate of the house by economic criteria]. Materialy mezhdunarodnoj nauchnotehnicheskoj konferencii «Nauchno-tehnicheskij progress $v$ sel'skohozjajstvennom proizvodstve. Agrarnaja nauka - sel'skohozjajstvennomu proizvodstvu Sibiri, Kazahstana, Mongolii, Belarusi i Bolgarii», 2016, pp. 18-22.

4. Kurilenko N.I., Davljatchin R.R., Ermolaev A.N. Osobennosti regulirovanija sistem gazovogo infrakrasnogo obogreva [Features of regulation of gas 
infrared heating systems]. Inzhenernyj vestnik Dona, 2015, no. 2-2(36)-126 p.

5. Sanzharovskaja M.I. Jenergosberezhenie pri primenenii infrakrasnogo izluchenija dlja otoplenija zhivotnovodcheskih i drugih pomeshhenij [Energy saving when using infrared radiation for heating livestock and other buildings]. Inzhenerno-tehnicheskoe obespechenie APK. Referativnyj zhurnal, 2008, no. 2, pp. 592.
6. Hajrullin D.A., Teregulov T.R. Princip infrakrasnogo obogreva [Principle of infrared heating]. European Science, 2016, no. 12 (22), pp.13-14.

7. Chulin, V.R., Shelehova I.Ju., Pozhidaev V.V. Infrakrasnye sistemy obogreva [Infrared heating systems]. Materialy mezhdunarodnoj nauchnoprakticheskoj konferencii «Rol' nauki v razvitii sovremennogo gosudarstva», 2018, pp. 133-139.

\section{Information about the Authors}

Aleksey V. Sklyar, Candidate of Sciences (Agriculture), Official Agent, Big Dutchman AG (holding) Auf der Lage 249377 Vechta-Calveslage Postfach 116349360 Vechta, Germany, vsklar41@mail.ru.

Margarita V. Postnova, Doctor of Biological Sciences, Chief Department of Bioengineering and Bioinformatics, Volgograd State University, Prosp. Universitetskiy, 100, 400062 Volgograd, Russian Federation, postnova@volsu.ru.

\section{Информация об авторах}

Алексей Владимирович Скляр, кандидат сельскохозяйственных наук, представитель OОО «Биг Дачмен», г. Москва, Российская Федерация; Big Dutchman AG (холдинг), Auf der Lage 249377 Vechta-Calveslage Postfach 116349360 Vechta Германия, vsklar41@mail.ru.

Маргарита Викторовна Постнова, доктор биологических наук, старший научный сотрудник, заведующий кафедрой биоинженерии и биоинформатики, Волгоградский государственный университет, просп. Университетский, 100, 400062 г. Волгоград, Российская Федерация, postnova@volsu.ru. 